\title{
The impact of low molecular weight heparin on obstetric outcomes among unexplained recurrent miscarriages complicated with methylenetetrahydrofolate reductase gene polymorphism
}

\author{
Orkun Cetin ${ }^{1}$, Erbil Karaman ${ }^{1}$, Numan Cim ${ }^{1}$, Deniz Dirik ${ }^{1}$, \\ Hanim Guler Sahin ${ }^{1}$, Erdal Kara ${ }^{2}$, Ramazan Esen ${ }^{2}$ \\ ${ }^{1}$ Department of Obstetrics and Gynecology, Faculty of Medicine, Yuzuncu Yil University, Van, Turkey \\ ${ }^{2}$ Department of Internal Medicine, Faculty of Medicine, Yuzuncu Yil University, Van, Turkey
}

\begin{abstract}
Objectives: The association between methylenetetrahydrofolate reductase gene polymorphisms and unexplained recurrent miscarriage is elusive. The recommendations for improving pregnancy outcomes in these patients keep changing based on the available evidence. The aim of this study is to analyze the impact of low molecular weight heparin on obstetric outcomes of recurrent miscarriage patients complicated with methylenetetrahydrofolate reductase gene polymorphism. Material and methods: We reviewed medical records of 121 patients with a history of recurrent miscarriage complicated by methylenetetrahydrofolate reductase gene polymorphisms, retrospectively. From among them, 68 patients were treated only with folic acid and iron. The remaining 53 patients were treated with folic acid, iron and prophylactic doses of low molecular weight heparin. The subsequent pregnancy outcomes of these patients were noted.

Results: The live birth rate was higher in patients with anticoagulant therapy than in patients without anticoagulant therapy (48.5\% vs. $69.8 \%$, respectively, p: 0.015$)$ and the congenital anomaly rate was lower in anticoagulant therapy group (17.6\% vs. 3.8\%, respectively, p: 0.022 ). The other obstetric outcomes were found to be similar between the two groups.

Conclusions: The current study demonstrated that low molecular weight heparin improved the live birth rates among unexplained recurrent miscarriage patients complicated with methylenetetrahydrofolate reductase gene polymorphisms. However, the routine use of low molecular weight heparin did not improve the late pregnancy complications in these selected patients in the eastern region of our country. Further studies are needed to discriminate the effect of anticoagulation on the live birth rate of each of methylenetetrahydrofolate reductase gene polymorphism type.

Key words: unexplained recurrent miscarriage, methylenetetrahydrofolate reductase gene polymorphism, low molecular weight heparin, obstetric outcomes
\end{abstract}

Ginekologia Polska 2017; 88, 5: 260-265

\section{INTRODUCTION}

Recurrent miscarriage (RM) is a major obstetric problem that is challenging for both: the patients as well as the clinicians. Approximately $3 \%$ of women in reproductive age experience recurrent pregnancy loss [1, 2]. The etiology is multifactorial and includes chromosomal abnormalities, uterine anatomical pathologies, endocrine dysfunctions, maternal autoimmune disorders, acquired or inherited thrombophilia and environmental causes [3]. Despite the availability of diagnostic methods such as hysteroscopy, hysterosalpingography, antiphospholipid antibody testing or parental karyotyping, the underlying pathology remains unidentified in $50 \%$ of cases which are defined as unexplained RMs [4]. Multiple pregnancy loss is also a risk factor for intrauterine growth restriction (IUGR), preterm delivery and fetal abnormalities [5]. Finally, a cohort study reports 
that patients with recurrent miscarriage represent a population that is at high risk for obstetric complications that require a close surveillance during the antenatal period $[5,6]$.

Increased homocysteine concentration in maternal circulation is associated with unexplained RM. Hyperhomocysteinemia was detected in approximately $30 \%$ of RM patients $[7,8]$. Since 5',10'-methylenetetrahydrofolate reductase (MTHFR) enzyme encoded by the MTHFR gene is necessary for the conversion of homocysteine to methionine, the reduction in enzyme activity results in a mild elevation of blood homocysteine levels [11]. The single nucleotide polymorphism of C677T and A1298C are the most commonly identified forms of MTHFR gene polymorphism. Patients homozygous for MTHFR C677T showed about $30 \%$ of normal enzyme activity while heterozygosity demonstrates $65 \%$ of normal enzyme activity. In contrast, such reduction in enzyme activity in women with MTHFR A1298C polymorphism was not demonstrated $[9,10]$. It would be reasonable then to assume that the A1298C type of polymorphism does not influence the homocysteine levels, hence it should not be linked to unexplained RM. Indeed, a recent meta-analysis has found that there is no relation between MTHFR A1298C polymorphism and unexplained recurrent pregnancy loss. However, it has also been found that the MTHFR C677T type was a contributor for recurrent pregnancy loss but in East Asians only [12, 13]. The debate on MTHFR gene polymorphism and unexplained $\mathrm{RM}$ remains elusive.

There is also no consensus about the use of low molecular weight heparin (LMWH) for preventing miscarriages. In recent Cochrane meta-analysis the authors did not recommend anticoagulants in RM patients beyond those complicated with inherited thrombophilia. They also suggested that pregnancy complications like preterm delivery, preeclampsia, IUGR and congenital abnormalities were not significantly affected by the use of aspirin or LMWH [14]. Despite this, empirical therapy for unexplained RM patients in form of a low dose aspirin and prophylactic doses of LMWH has been a widespread clinical practice in several clinics around Turkey [15].

\section{OBJECTIVES}

We performed a retrospective study to evaluate the impact of LMWH on obstetric outcomes of recurrent miscarriage patients complicated with MTHFR gene polymorphism in our tertiary referral hospital in eastern Turkey.

\section{MATERIAL AND METHODS}

This single center retrospective study was conducted at Yuzuncu Yıl University Medical Faculty, Obstetrics and Gynecology clinic in Van, Turkey. This study was approved by the institutional ethics committee of Yuzuncu Yıl University. Medical records of 249 women with a history of recurrent miscarriage were reviewed. They were tested for inherited thrombophilia between January 2010 and June 2015 in our tertiary referral center. From among them 121 women aged 18-45 with MTHFR gene polymorphism were selected into the study population. The polymorphism composed of MTHFR C677T and A1298C gene homozygosity or heterozygosity and compound heterozygosity. The selected women were followed up at our obstetric unit during their pregnancy. The patients with anatomic, hormonal, chromosomal, infectious and autoimmune factors for recurrent miscarriage were excluded from the study. The laboratory genotyping of the MTHFR gene was performed by the Polymerase Chain Reaction which was performed by a Perkin Elmer 9600 and the profile consisted of an initial melting step of 2 min at $94^{\circ} \mathrm{C}$; followed by 35 cycles of $30 \mathrm{~s}$ at $94^{\circ} \mathrm{C}, 30 \mathrm{~s}$ at $61^{\circ} \mathrm{C}$, and $30 \mathrm{~s}$ at $72^{\circ} \mathrm{C}$; and a final elongation step of $7 \mathrm{~min}$ at $72^{\circ} \mathrm{C}$. The normal and mutant heterozygous or homozygous genotype profiles of each of the genes were determined using the enclosed Collector $^{\mathrm{TM}}$ sheet. Patients were divided into two groups: Anticoagulant free group (Group A) (n:68) and anticoagulant therapy group (Group B) (n: 53). The women in group A received only oral folic acid (5 mg/day) and iron (80 mg elementary iron/day, iron [II] sulphate) during their pregnancy. The women in group $B$ received oral folic acid ( $5 \mathrm{mg} /$ day), iron ( $80 \mathrm{mg}$ elementary iron/day, iron [II] sulphate) and prophylactic dose of LMWH (enoxaparin $40 \mathrm{mg} /$ day or bemiparin $3500 \mathrm{IU} /$ day, subcutaneously). LMWH therapy was started between $6^{\text {th }}$ and $8^{\text {th }}$ week of pregnancy and continued until delivery. The primary outcome was live birth. Among secondary outcomes there were early-late miscarriages, stillbirths, preterm births, congenital anomalies, obstetric complications and short-term neonatal events. These pregnancy outcomes of the patients were reviewed from the hospital's medical records.

RM was described as three or more consecutive spontaneous pregnancy losses before $22^{\text {nd }}$ week of gestation (early or late miscarriage). All miscarriages were confirmed either by positive urine/serum HCG and sonography or histology of uterine curettage. Early miscarriage was defined as a pregnancy loss at $<12$ weeks of gestation. Late miscarriage was defined as a pregnancy loss between 12 and 22 weeks of gestation. Stillbirth was defined as a pregnancy loss $>22$ weeks of gestation. Intrauterine growth restriction (IUGR) was defined as a birthweight $<5^{\text {th }}$ percentile [16]. Severe preeclampsia was described as blood pressure $>160 / 110 \mathrm{~mm} \mathrm{Hg}$ recorded at least $6 \mathrm{~h}$ apart and proteinuria $>5 \mathrm{gm}$ in a 24-hour urine sample. In addition, any patient with cerebral or visual impairment, persistent epigastric pain, pulmonary edema or cyanosis was diagnosed with severe preeclampsia [17].

Descriptive statistics for the studied variables (characteristics) were presented as Mean, Standard Deviation 
values. Continuous variables were compared among the two groups using Student T-test. Z-ratio test was used to examine the association between categorical variables. Statistical significance levels were set to $5 \%$. The SPSS (IBM SPSS Statistics for Windows, Version 22.0. IBM Corp. Released 2013. Armonk, NY: IBM Corp.) statistical program was used for all statistical computations.

\section{RESULTS}

We obtained the records of $121 \mathrm{RM}$ patients diagnosed with MTHFR gene polymorphism. 68 patients were in group $A$ and 53 patients were in group B. Group A involved 22 women with MTHFR A1298C heterozygous, 8 women with MTHFR A1298C homozygous, 12 women with MTHFR C677T heterozygous, 12 women with MTHFR C677T homozygous and 14 women with combination of MTHFR A1298C and MTHFR C677T heterozygous. Group B involved 9 women with MTHFR A1298C heterozygous, 13 women with MTHFR A1298C homozygous, 8 women with MTHFR C677T heterozygous, 7 women with MTHFR C677T homozygous and 16 women with combination of MTHFR A1298C and MTHFR C677T heterozygous. The clinical and obstetric outcomes of the patients were presented in Table 1. There was no significant difference between the groups in terms of maternal age, early miscarriage rate, late miscarriage rate, stillbirth rate, preterm birth rate, chorioamnionitis rate, preeclampsia rate and IUGR rate. The total live birth rate was $57.9 \%(70 / 121)$ in the study and this rate was higher in group B (48.5\% vs. $69.8 \%$ respectively, p: 0.015$)$. The total preterm birth rate was $22.3 \%(27 / 121)$ in the study. There was no significant difference between the groups in preterm delivery rate $(16.2 \%[11 / 68]$ vs. $30.2 \%$ [16/53] respectively, p: 0.070). Also, extremely preterm (24-28 gestational weeks), very preterm (28-32 gestational weeks) and late preterm birth rates (32-36 gestational weeks) were similar between the groups ( $p: 0.653, p: 0.178, p: 0.403$, respectively). The total IUGR rate was $5.8 \%(7 / 121)$ in the study and this rate was similar between each group $(7.4 \%$ vs. $3.8 \%$ respectively, p: 0.465$)$. The total congenital anomaly rate was $11.6 \%$ $(14 / 121)$ in the study and congenital anomalies were more frequent in group A ( $17.6 \%$ vs. $3.8 \%$ respectively, p: 0.022$)$. Group A involved 5 fetuses with neural tube defect, 3 fetuses with diaphragm hernia, 1 fetus with esophagus atresia, 2 fetuses with non-immune hydrops fetalis and 1 fetus with hypo plastic left ventricle syndrome. In group B, only 2 fetuses had neural tube defect.

The delivery and short term neonatal outcomes of the patients were shown in Table 2. The total mean gestational age at birth was $33.81 \pm 5.09$ in the study. There were no significant differences between the groups in terms of gestational age at birth, delivery type, delivery complications (fetal distress, prolonged labor, placental abruption, severe preeclampsia and placenta previa), birthweight, Apgar scores and neonatal intensive care unit (NICU) admission. The total NICU admission rate was $19.0 \%(23 / 121)$ in the study. The total fetal distress, placental abruption and severe preeclampsia rates were as $17.4 \%(21 / 121), 5.0 \%(6 / 121)$ and $3.3 \%(4 / 121)$, respectively in the study.

\section{DISCUSSION}

The current study demonstrated that unexplained RM patients with MTHFR gene polymorphism, who received

Table 1. The comparison of the clinical and obstetric outcomes of the patients between the groups

\begin{tabular}{|c|c|c|c|}
\hline & $\begin{array}{l}\text { LMWH (-) group } \\
\quad(n=68)\end{array}$ & $\begin{array}{l}\text { LMWH (+) group } \\
\qquad(n=53)\end{array}$ & $\mathbf{p}$ \\
\hline Maternal age & $28.40 \pm 5.20$ & $28.36 \pm 5.77$ & $0.969^{*}$ \\
\hline Number of early miscarriage & 13/68 (13.1\%) & $6 / 53(11.3 \%)$ & $0.227^{\#}$ \\
\hline Number of late miscarriage & $16 / 68(23.5 \%)$ & $13 / 53(24.5 \%)$ & $0.899^{\#}$ \\
\hline Number of stillbirth & 13/68 (19.1\%) & $5 / 53(9.4 \%)$ & $0.120^{\#}$ \\
\hline Preterm birth & $11 / 68(16.2 \%)$ & $16 / 53(30.2 \%)$ & $0.070^{\#}$ \\
\hline 24-28 gestational weeks & 6/68 (8.8\%) & $6 / 53(11.3 \%)$ & $0.653^{\#}$ \\
\hline 28-32 gestational weeks & $3 / 68(26.6 \%)$ & $6 / 53(38.9 \%)$ & $0.178^{\#}$ \\
\hline 32-36 gestational weeks & $2 / 68(26.9 \%)$ & $4 / 53(33.3 \%)$ & $0.403^{\#}$ \\
\hline Chorioamnionitis & $4 / 68(4.4 \%)$ & $2 / 53(3.8 \%)$ & $0.695^{\#}$ \\
\hline Preeclampsia & 6/68 (8.8\%) & $3 / 53(5.7 \%)$ & $0.730^{\#}$ \\
\hline IUGR & $5 / 68(7.4 \%)$ & $2 / 53(3.8 \%)$ & $0.465^{\#}$ \\
\hline Congenital anomalies & $12 / 68(17.6 \%)$ & $2 / 53(3.8 \%)$ & $0.022^{\#}$ \\
\hline Live birth & $33 / 68(48.5 \%)$ & $37 / 53(69.8 \%)$ & $0.015^{\#}$ \\
\hline
\end{tabular}

*Student T-test was used to compare continuous variables; ${ }^{\text {ZZ }}$ ratio test was used to compare categorical variables; LMWH (-) — low molecular weight heparin absent group; LMWH (+) - low molecular weight present group; IUGR — intrauterine growth restriction 
Table 2. The comparison of the delivery and short term neonatal outcomes of the patients between the groups

\begin{tabular}{|c|c|c|c|}
\hline & $\begin{array}{l}\text { LMWH (-) group } \\
\qquad(n=68)\end{array}$ & $\begin{array}{l}\text { LMWH (+) group } \\
\qquad(n=53)\end{array}$ & $\mathbf{p}$ \\
\hline Delivery week & $32.75 \pm 5.16$ & $34.88 \pm 4.87$ & $0.060^{*}$ \\
\hline Vaginal delivery & $19 / 68(27.9 \%)$ & $14 / 53(26.4 \%)$ & $0.851^{\#}$ \\
\hline Cesarean-section & $22 / 68(32.4 \%)$ & $26 / 53(49.1 \%)$ & $0.256^{\#}$ \\
\hline Fetal distress & $10 / 68(14.7 \%)$ & $11 / 53(20.8 \%)$ & $0.390^{\#}$ \\
\hline Prolonged labor & $5 / 68(7.4 \%)$ & $10 / 53(18.9 \%)$ & $0.065^{\#}$ \\
\hline Abruption of placenta & $4 / 68(5.9 \%)$ & $2 / 53(3.8 \%)$ & $0.586^{\#}$ \\
\hline Severe preeclampsia & $2 / 68(2.9 \%)$ & $2 / 53(3.8 \%)$ & $0.802^{\#}$ \\
\hline Placenta previa & $1 / 68(3.0 \%)$ & $1 / 53(2.7 \%)$ & $0.861^{\#}$ \\
\hline Birthweight & $2174.14 \pm 1140.20$ & $2543.75 \pm 1105.42$ & $0.159 *$ \\
\hline Apgar 1. minute & $5.28 \pm 1.59$ & $5.92 \pm 1.12$ & $0.056^{*}$ \\
\hline Apgar 5. minutes & $6.78 \pm 1.74$ & $7.43 \pm 1.04$ & $0.059 *$ \\
\hline NICU admission & $13 / 68(19.1 \%)$ & $10 / 53(18.9 \%)$ & $0.972^{\#}$ \\
\hline
\end{tabular}

*Student T-test was used to compare continuous variables; \#Z ratio test was used to compare categorical variables; LMWH (-) — low molecular weight heparin absent group; LMWH (+) — low molecular weight present group; NICU — neonatal intensive care unit

anticoagulant therapy (LMWH) during the period of their new pregnancy, had a lower risk for congenital anomalies. Moreover, anticoagulant therapy improved the live birth rates among these patients. However, anticoagulant therapy did not have any beneficial effect on the rate of early-late miscarriages, stillbirth, preterm delivery, preeclampsia, IUGR, placental abruption, Apgar scores or NICU admission among these patients.

There is a debate on the usage of anticoagulant therapy in women with unexplained RM. Kaandorp et al. stated that aspirin or LMWH did not improve live birth rate in women with unexplained RM [18]. Similarly, the recent Cochrane review suggests that the live birth rate is not affected by LMWH treatment in unexplained RM patients [14]. In opposition to that stands a recent study from Turkey reporting positive effects of LMWH on live birth rate in recurrent miscarriage patients who used LMWH when compared to patients without LMWH treatment [15]. Our study in turn shows that LMWH improves the live birth rate among RM patients with MTHFR gene polymorphism. The apparent heterogeneity of study populations in these different clinical trials may be the origin for conflicting results. Furthermore, most of the studies mentioned above did not include women with MTHFR gene polymorphism [15, 18]. It is of vital importance that our study population is composed of selected groups of unexplained RM patients with different MTHFR gene polymorphisms.

Many previous studies reported that there were possible associations between MTHFR gene polymorphism (especially MTHFR C677T polymorphism) and fetal neural tube defects. However, MTHFR gene polymorphism is not the main factor behind such congenital malformations. Moreover, maternal blood homocysteine levels can also be altered by some genetic and environmental factors [7, 8]. Yet, the fetal neural tube defect rate in our study was $5.9 \%$ (7/121), which is higher than in the general population (0.5-2/1000) [19].

$\mathrm{RM}$ is also associated with fetal anomalies [5]. Two clinical trials compared congenital abnormalities in RM patients and they reported similar rates between patients that did and did not receive LMWH $[20,21]$. In our study, congenital abnormalities were more frequent in $\mathrm{LMWH}$-free group (group A). Although our study did not intend to investigate this issue, we did not reveal any association between these abnormalities and LMWH. Hence, such observation cannot be explained by the usage of $\mathrm{LMWH}$.

High levels of maternal homocysteine have been associated with preeclampsia and abruption of placenta [22, 23]. It has been established that hyperhomocysteinemia is a contributor to endothelial dysfunction in pregnancy [23]. In a recent meta-analysis it was demonstrated that MTHFR C677T polymorphism was associated with preeclampsia in Asian and white population while MTHFR A1298C polymorphism had no such association [26]. Also, events like necrosis, acute and chronic inflammation or vascular thrombosis are more prominent in the deciduae of RM patients compared with normal pregnancies [27]. These factors are possible causes of late pregnancy complications like preeclampsia, placental abruption and late pregnancy complications in RM [5, 26]. Some randomized controlled trials determined that $\mathrm{LMWH}$ is a preventive treatment for placenta mediated pregnancy complications [27, 28]. However, Martinelli et al. suggested that LMWH should not be routinely administered to prevent recurrence of placenta-mediated pregnancy complications [29]. Badawy et al. did not detect 
any therapeutic effect of LMWH on obstetric and neonatal complications in RM patients either [21]. Our results are in accordance with these studies. We did not find any beneficial effect of LMWH on obstetric or neonatal complications in the selected group of different MTHFR gene polymorphisms among RM patients.

The present study has several limitations. The study is retrospective and small in sample size. We focused only on MTHFR gene polymorphism and the effects of anticoagulant use in RM patients without controlling for maternal folic acid and homocysteine concentrations. Also, we included all subgroups of MTHFR gene polymorphism, thus the heterogeneity of the study population may cause a potential bias. The clinicians advised different LMWH regimens to the patients according to their clinical experience, so we could not standardize the LMWH regimen. Some patients were administered enoxaparin and some bemiparin for $\mathrm{LMWH}$ prophylaxis.

\section{CONCLUSIONS}

Based on the available evidence, the association between MTHFR gene polymorphism and RM, as well as the usage of LMWH for preventing obstetric complications or empiric anticoagulation for unexplained RM, all remain debatable topics in the literature. However, in current clinical practice many obstetricians all around Turkey still use anticoagulation treatment modalities for the aforementioned clinical indications. The current indiscriminate use of LMWH for all RM patients in Turkey should be changed according to the evidence based guidelines. In our opinion, specific subgroups of RM patients might benefit from new treatment strategies. As a result of this study, despite a limited number of patients, we propose that anticoagulation therapy be preferred for improving live birth rate in unexplained RM patients complicated with MTHFR gene polymorphism only. We also call for further studies to discriminate the effect of LMWH on the live birth rate in specific subgroups of MTHFR gene polymorphism (homozygous vs. heterozygous). We also conclude that in our patients selected from eastern region of Turkey with MTHFR gene polymorphism, the routine use of low molecular weight heparin did not improve the late pregnancy complications.

\section{Acknowledgment}

This single center, retrospective study was conducted at Yuzuncu Yıl University Medical Faculty, Obstetrics and Gynecology clinic in Van between January 2010 and June 2015.

\section{Conflict of interest}

The authors declare that they have no conflict of interest. The authors indicated that there was no financial relationship with the organization that sponsored the research. The authors had full control of all primary data and we agree to allow the Journal to review our data if requested.

\section{REFERENCES}

1. Regan L, Rai R. Epidemiology and the medical causes of miscarriage Baillieres Best Pract Res Clin Obstet Gynaecol. 2000; 14(5): 839-854, doi: 10.1053/beog.2000.0123, indexed in Pubmed: 11023804.

2. Mukherjee S, Velez Edwards DR, Baird DD, et al. Risk of miscarriage among black women and white women in a U.S. Prospective Cohort Study. Am J Epidemiol. 2013; 177(11): 1271-1278, doi: 10.1093/aje/kws393, indexed in Pubmed: 23558353.

3. Rai R, Regan L. Recurrent miscarriage. The Lancet. 2006; 368(9535): 601-611, doi: 10.1016/s0140-6736(06)69204-0.

4. American College of Obstetricians and Gynecologists. ACOG practice bulletin. Management of recurrent pregnancy loss. Int J Gynaecol Obstet. 2002; 78(2): 179-190.

5. Jivraj S, Anstie B, Cheong YC, et al. Obstetric and neonatal outcome in women with a history of recurrent miscarriage: a cohort study. Hum Reprod. 2001; 16(1): 102-106, indexed in Pubmed: 11139545.

6. Christiansen OB, Mathiesen O, Lauritsen JG, et al. Study of the birthweight of parents experiencing unexplained recurrent miscarriages. Br J Obstet Gynaecol. 1992; 99(5): 408-411, indexed in Pubmed: 1622914.

7. Goddijn-Wessel TA, Wouters MG, van de Molen EF, et al. Hyperhomocysteinaemia and recurrent spontaneous abortion or abruptio placentae. Lancet. 1992; 339(8801): 1122-1123, indexed in Pubmed: 1349147.

8. Wouters MG, Boers GH, Blom HJ, et al. Hyperhomocysteinemia: a risk factor in women with unexplained recurrent early pregnancy loss. Fertil Steril. 1993; 60(5): 820-825, indexed in Pubmed: 8224267.

9. Frosst $\mathrm{P}, \mathrm{Blom} \mathrm{HJ}, \mathrm{Milos} \mathrm{R}$, et al. A candidate genetic risk factor for vascular disease: a common mutation in methylenetetrahydrofolate reductase. Nat Genet. 1995; 10(1): 111-113, doi: 10.1038/ng0595-111, indexed in Pubmed: 7647779.

10. Zetterberg $\mathrm{H}$. Methylenetetrahydrofolate reductase and transcobalamin genetic polymorphisms in human spontaneous abortion: biological and clinical implications. Reprod Biol Endocrinol. 2004; 2: 7, doi: 10.1186/1477-7827-2-7, indexed in Pubmed: 14969589.

11. Homocysteine Studies Collaboration. Homocysteine and risk of ischemic heart disease and stroke: a meta-analysis. JAMA. 2002; 288(16): 2015-2022, indexed in Pubmed: 12387654.

12. Cao $Y, X u$ J, Zhang $Z$, et al. Association study between methylenetetrahydrofolate reductase polymorphisms and unexplained recurrent pregnancy loss: a meta-analysis. Gene. 2013; 514(2): 105-111, doi: 10.1016/j. gene.2012.10.091, indexed in Pubmed: 23201418.

13. Ren A, Wang J. Methylenetetrahydrofolate reductase C677T polymorphism and the risk of unexplained recurrent pregnancy loss: a meta-analysis. Fertil Steril. 2006; 86(6): 1716-1722, doi: 10.1016/j. fertnstert.2006.05.052, indexed in Pubmed: 17074326.

14. de Jong PG, Kaandorp S, Di Nisio M, et al. Aspirin and/or heparin for women with unexplained recurrent miscarriage with or without inherited thrombophilia. Cochrane Database Syst Rev. 2014(7): CD004734, doi: 10.1002/14651858.CD004734.pub4, indexed in Pubmed: 24995856.

15. Yuksel H, Kayatas S, Boza AT, et al. Low molecular weight heparin use in unexplained recurrent miscarriage. Pak J Med Sci. 2014; 30(6): 1232-1237, doi: 10.12669/pjms.306.5477, indexed in Pubmed: 25674114.

16. Seeds JW. Impaired fetal growth: definition and clinical diagnosis. Obstet Gynecol. 1984; 64(3): 303-310, indexed in Pubmed: 6379528.

17. Cunningham G, Leveno K, Bloom S. Williams Obstetrics, 22nd ed. New York: McGraw Hill 2005.

18. Kaandorp SP, Goddijn M, van der Post JAM, et al. Aspirin plus heparin or aspirin alone in women with recurrent miscarriage. N Engl J Med. 2010; 362(17): 1586-1596, doi: 10.1056/NEJMoa1000641, indexed in Pubmed: 20335572.

19. Copp AJ, Stanier P, Greene NDE. Neural tube defects: recent advances, unsolved questions, and controversies. Lancet Neurol. 2013; 12(8): $799-$ -810, doi: 10.1016/S1474-4422(13)70110-8, indexed in Pubmed: 23790957.

20. Fawzy M, Shokeir T, El-Tatongy M, et al. Treatment options and pregnancy outcome in women with idiopathic recurrent miscarriage: a randomized placebo-controlled study. Arch Gynecol Obstet. 2008; 278(1): 33-38, doi: 10.1007/s00404-007-0527-x, indexed in Pubmed: 18071727.

21. Badawy AM, Khiary M, Sherif LS, et al. Low-molecular weight heparin in patients with recurrent early miscarriages of unknown aetiology. J Obstet Gynaecol. 2008; 28(3): 280-284, doi: 10.1080/01443610802042688, indexed in Pubmed: 18569468. 
22. Zhang XY, Sun J. The relationship between plasma homocysteine and preeclampsia. Chin J Perinat Med. 2008; 11: 245-248.

23. Powers RW, Evans RW, Majors AK, et al. Plasma homocysteine concentration is increased in preeclampsia and is associated with evidence of endothelial activation. Am J Obstet Gynecol. 1998; 179 (6 Pt 1): 1605-1611, indexed in Pubmed: 9855605.

24. Li X, Luo YaL, Zhang QH, et al. Methylenetetrahydrofolate reductase gene C677T, A1298C polymorphisms and pre-eclampsia risk: a meta-analysis. Mol Biol Rep. 2014; 41(8): 5435-5448, doi: 10.1007/s11033014-3415-z, indexed in Pubmed: 24898880.

25. Van Horn JT, Craven C, Ward K, et al. Histologic features of placentas and abortion specimens from women with antiphospholipid and antiphospholipid-like syndromes. Placenta. 2004; 25(7):642-648, doi: 10.1016/j. placenta.2003.12.006, indexed in Pubmed: 15193871.

26. Bates SM, Greer IA, Hirsh J, et al. Use of antithrombotic agents during pregnancy: the Seventh ACCP Conference on Antithrombotic and Thrombolytic Therapy. Chest. 2004; 126(3 Suppl): 627S-644S, doi: 10.1378/chest.126.3_suppl.627S, indexed in Pubmed: 15383488.

27. Gris JC, Chauleur C, Faillie JL, et al. Enoxaparin for the secondary prevention of placental vascular complications in women with abruptio placentae. The pilot randomised controlled NOH-AP trial. Thromb Haemost. 2010; 104(4): 771-779, doi: 10.1160/TH10-03-0167, indexed in Pubmed: 20694277.

28. de Vries JIP, van Pampus MG, Hague WM, et al. FRUIT Investigators. Low-molecular-weight heparin added to aspirin in the prevention of recurrent early-onset pre-eclampsia in women with inheritable thrombophilia: the FRUIT-RCT. J Thromb Haemost. 2012; 10(1): 64-72, doi: 10.1111/j.1538-7836.2011.04553.x, indexed in Pubmed: 22118560.

29. Martinelli I, Ruggenenti P, Cetin I, et al. HAPPY Study Group. Heparin in pregnant women with previous placenta-mediated pregnancy complications: a prospective, randomized, multicenter, controlled clinical trial. Blood. 2012; 119(14): 3269-3275, doi: 10.1182/blood-2011-11-391383, indexed in Pubmed: 22289887. 